\title{
Performance of Macrobrachium rosenbergii in Perennial Reservoirs: A Comparative Assessment of Fisheries in Five Perennial Reservoirs in the Northern Province of Sri Lanka
}

\author{
R. Rajeevan*, U. Edirisinghe ${ }^{1}$ and A.R.S.B. Athauda ${ }^{1}$ \\ Postgraduate Institute of Agriculture \\ University of Peradeniya \\ Sri Lanka
}

\begin{abstract}
The giant freshwater prawn (Macrobrachium rosenbergii), was first introduced to the reservoirs in the Northern Province of Sri Lanka. Studies on the performances of introduced species in reservoirs are essential for development of fisheries and management. The objective of the present study was to evaluate and compare the performance of $M$. rosenbergii production in five selected perennial reservoirs. Primary data relating to the fisheries of the reservoirs and relevant socio-economic data were gathered through field data collection and questionnaire survey conducted in 2016 and 2017. Unit production of $M$. rosenbergii in 2017 in the Vavunikulam, Muthayankattu, Puthumurippu, Kalmadu and Muhathankulam reservoirs was $5.3 \mathrm{~kg} / \mathrm{ha}, 3.2 \mathrm{~kg} / \mathrm{ha}, 13.6 \mathrm{~kg} / \mathrm{ha}, 21.8 \mathrm{~kg} / \mathrm{ha}, 12.9 \mathrm{~kg} / \mathrm{ha}$, respectively with a farm-gate values of $6.84,4.39,2.1,1.59$, and 2.85 million Sri Lankan rupees, respectively. Relative abundance, economic (total farm-gate price) contribution and recapture rate of $M$. rosenbergii in the catch, ranged between $2.3 \%-20 \%, 13.5 \%-72.3 \%$ and $1.44 \%-6.49 \%$, respectively across the reservoirs. Even though the recapture rate was low, catching of $M$. rosenbergii improved the livelihood of fishers while increasing their interest in fisheries. Size of the reservoir, stocking density, fishing intensity and gear specification, rainfall, wind and socio-economic factors significantly influenced the catch of $M$. rosenbergii in the selected reservoirs. The results showed that the introduction of $M$. rosenbergii as culturebased fisheries in the selected five reservoirs has achieved considerable success, particularly in terms of economic benefits.
\end{abstract}

Keywords: Macrobrachium rosenbergii, perennial reservoirs, culture-based fisheries, $P L$ stocking, performance

\section{INTRODUCTION}

Sri Lanka has many reservoirs of varying nature and scale including seasonal and perennial reservoirs of large, medium and small sizes. While the primary purposes of these reservoirs are irrigation and generation of hydroelectricity, they contribute for fisheries production too, similar to reservoirs in other parts of Asia (Amarasinghe et al., 2001). Making use of reservoirs for fisheries production in Asia in the past few decades have contributed to increase both production of food protein and income of rural dwellers (De Silva, 1996; Amarasinghe et al., 2001). There are few factors influencing the yield from reservoirs, such as reservoir morphometry, hydro-climatic factors, species composition, fishing effort, gear specification,

1 Department of Animal Science, Faculty of Agriculture, University of Peradeniya, Sri Lanka

* Corresponding author: r.rajeevan88@gmail.com 
stocking of post-larvae, socioeconomic factors and behavior of fish and prawn species (Craig et al., 1985; De Silva, 1996; Gray et al., 2005). Reservoir fisheries show unique characteristics compared to other types of fisheries, where majority of reservoir fisheries are artisanal and highly seasonal integrating well with the ecology of fishery resources (Welcomme, 2001). In Sri Lanka, fishing methods mainly depend on multi-mesh gillnets which are highly selective targeting mainly exotic tilapia species (De Silva, 1988). Due to the seasonal variations in the size of the stocks of these target species, reservoir fishers are compelled to use different mesh compositions of gillnets during different seasons (Pet et al., 1999).

Introducing and stocking of desirable fish species to reservoirs is commonly practiced worldwide to improve production though the stocking is not the sole mechanism for improvement of fishery (Quirõs and Boveri, 1999). FAO (1999) indicated that fish stocking in Asia and Oceania is practiced for increasing yields, production of food and generation of income. Stocking can be categorized according to the purpose, which include stocking for pollution mitigation, for enhancement, for restoration and for creation of new fisheries. For the purpose of creating new fisheries, a new fish stock is introduced to a river, lake or reservoir, where the particular fish did not exist earlier due to natural habitat related barriers or evolutionary reasons. Establishment of new fish species is also done for reasons including, to increase diversity of species, to fulfill an existing niche gap and to increase fish yield (Cowx, 1999). Success of stocking can be measured by increase in yield, comparison between stocked and non-stocked waters and increase of income to fishers/stakeholders. Success of a stocking program may get impacted by factors such as stocking density and ecological carrying capacity of the receiving environment, age and size of fish at stocking, condition and health of stocked seed, genetic factors, suitability of habitat, feeds, competitors and predators, timing of stocking and release methods (Li, 1999; Brown and Day, 2002). The influence of those factor could differ among species, habitats as well as in time and space (Brown and Day, 2002).

The giant freshwater prawn, Macrobrachium rosenbergii is one of the most economically important prawn species in the world (New, 2017). Freshwater prawn farming has become a crucial and growing contributor to global aquaculture both in terms of quantity and value (FAO, 2017). Capture fisheries in inland waters, culture based fisheries and shrimp farming are part of inland fisheries in Sri Lanka (Amarasinghe, 2014). With the emerging interest in aquaculture in Sri Lanka, M. rosenbergii has become a notable species due to its rich taste, high price and cultivable quantities that make it a suitable candidate for extensive and intensive culture both in fresh and brackish waters. M. rosenbergii culture in Sri Lanka is limited mainly due to lack of freshwater prawn seeds which amounted only 60.9 million in 2017 (NAQDA, 2018). Therefore, improved breeding technique and increase in the production of seeds are essential for increasing freshwater prawn production. As a strategy to improve and expand the freshwater prawn production, NAQDA has launched free stocking program of $M$. rosenbergii in selected perennial and seasonal reservoirs. However, fisheries development was not given due attention in the Northern Province until recently. In this study, M. rosenbergii was introduced for the first time in all five selected reservoirs in the Northern Province. Studies focusing on the performances of introduced species in reservoirs are essential for planning of reservoir fisheries development and management. Thus, the objective of the present study was to evaluate and compare performances of introduced $M$. rosenbergii production in the five selected perennial reservoirs. 


\section{METHODOLOGY}

The study was conducted in five perennial reservoirs (Figure 1) in the Northern Province of Sri Lanka, viz., Vavunikulam (R1), Muthayankattu (R2), Puthumurippu (R3), Kalmadu (R4) and Muhathankulam (R5) with areas at full supply level of 1275 ha, 1255 ha, 151 ha, 74 ha and 211 ha, respectively. Among the five reservoirs, Vavunikulam and Muthayankattu were categorized as large reservoirs and Puthumurippu, Kalmadu and Muhathankulam were categorized as small reservoirs for comparison purposes. Fishers are registered under respective fisheries societies for getting permits for fisheries. The number of registered fishers of Vavunikulam, Muthayankattu, Puthumurippu, Kalmadu and Muhathankulam are 84, 90, 21, 21 , and 65 respectively. The five reservoirs were stocked with exotic tilapia, carp species and native $M$. rosenbergii. Performance evaluation and comparison of reservoirs were done based on $M$. rosenbergii production along with total fish production and other factors such as socioeconomic, hydro-climatic and anthropogenic factors.
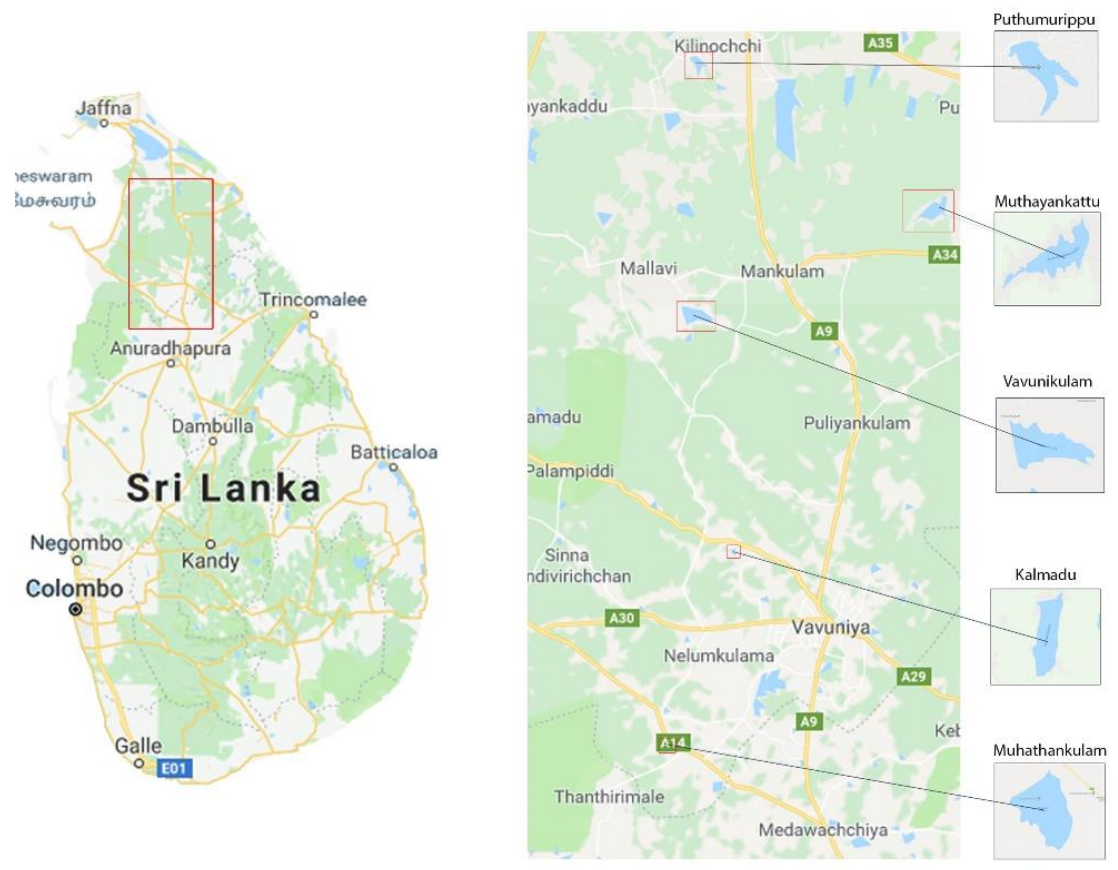

Figure 1. Locations of the selected reservoirs

Field data of the fived reservoirs was gathered on a biweekly basis in the years 2016 and 2017. The type of data included catch of $M$. rosenbergii (number and weight of both males and females), total fish production (number of individuals and weight), number of active fishers and canoes, type of gear, number of M. rosenbergii post larvae (PL)stocked, stocking time and their cost and farm-gate price of $M$. rosenbergii and other fish species. In addition, socioeconomic and other factors affecting the catch of $M$. rosenbergii was gathered by a questionnaire survey of 190 fishers and also by observations. Furthermore, recapture rate, return on investment and contribution of $M$. rosenbergii to reservoir fisheries on both weight and economic value basis were calculated for each reservoir. Relationship between the different parameters, such as yield $\left(\mathrm{kg} \mathrm{ha}^{-1}\right.$ day $\left.^{-1}\right)$, catch per unit effort (CPUE: 
$\mathrm{kg} /$ fisherman/day), fishing effort (fishermen $\mathrm{km}^{-2}$ ), stocking density (PL/ ha) and area at full supply level (FSL: ha) were determined by regression analyses and Pearson correlations using Minitab 17 statistical software and MS Excel (MS Office 2016).

\section{RESULTS AND DISCUSSION}

\section{Assessment of artisanal fisheries of five perennial reservoirs}

A total of 94144 individuals were quantified in the catch between 2016 and 2017, which comprised of 27 fish species and 2 freshwater prawn species. The larger reservoirs of Vavunikulam (65.4\%) and Muthayankattu (55.8\%) were dominated with exotic species, while Kalmadu (64.34\%) and Muhathankulam reservoirs (67\%) were dominated with non-stocked native species and the Puthumurippu reservoir had almost equal amounts of stocked and nonstocked species (Table 1). However, in all the reservoirs Nile Tilapia (O. niloticus) had the highest abundance among all the species in the catch. After the introduction and continuous stocking of $M$. rosenbergii, the relative abundance of Tilapia, Carp and most of the native species decreased, while $M$. rosenbergii increased in catch.

Table 1. Relative abundance of fish and prawn species at selected reservoirs

\begin{tabular}{ccccccccccc}
\hline Species & \multicolumn{2}{c}{ Vavunikulam } & \multicolumn{2}{c}{ Muthayankattu } & \multicolumn{2}{c}{ Puthumurippu } & \multicolumn{2}{c}{ Kalmadu } & \multicolumn{2}{c}{ Muhathankulam } \\
& $\mathbf{2 0 1 6}$ & $\mathbf{2 0 1 7}$ & $\mathbf{2 0 1 6}$ & $\mathbf{2 0 1 7}$ & $\mathbf{2 0 1 6}$ & $\mathbf{2 0 1 7}$ & $\mathbf{2 0 1 6}$ & $\mathbf{2 0 1 7}$ & $\mathbf{2 0 1 6}$ & $\mathbf{2 0 1 7}$ \\
\hline Tilapia & 64.03 & 63.68 & 53.17 & 52.12 & 30.1 & 22.78 & 19.21 & 17.15 & 24.03 & 21.77 \\
Carp & 1.74 & 1.27 & 3.23 & 3.17 & 13.16 & 11.25 & 11.05 & 11.23 & 7.7 & 7.51 \\
Native & 32.94 & 32.47 & 42.7 & 42.05 & 56.74 & 44.3 & 66.8 & 61.88 & 67.34 & 66.63 \\
FWP & 1.28 & 2.59 & 0.91 & 2.64 & - & 21.67 & 2.95 & 9.74 & 0.92 & 4.1 \\
\hline FWP
\end{tabular}

FWP: Machrobrachium rosenbergii

The relationship between Yield $\left(\mathrm{kg} \mathrm{ha}^{-1} \mathrm{day}^{-1}\right)$ and fishing effort was similar across all the selected five reservoirs (Figure 2).
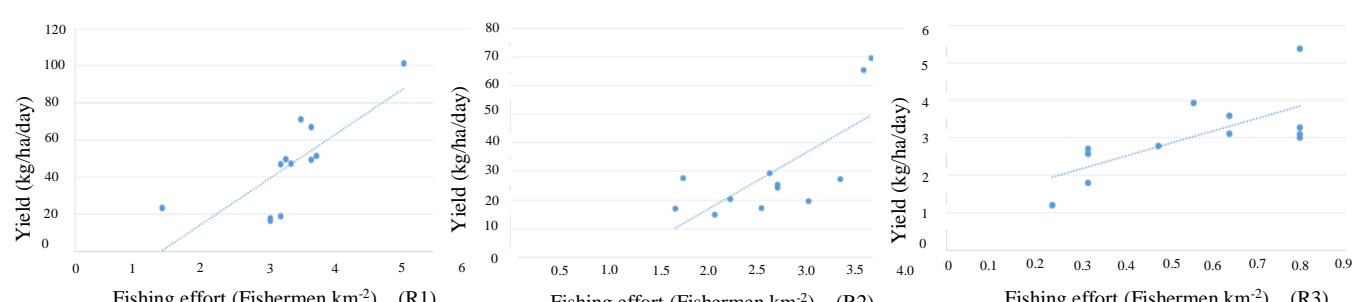

Fishing effort (Fishermen $\mathrm{km}^{-2}$ ) (R1)
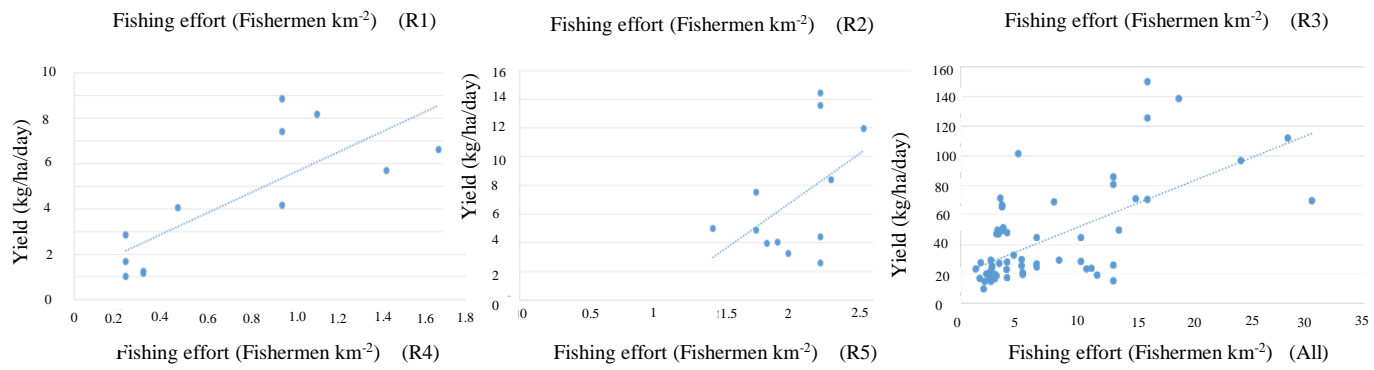

Figure 2. Relationship between yield and fishing effort of five reservoirs R1:Vavunikulam, R2:Muthayankattu, R3:Puthumurippu, R4:Kalmadu, R5:Muhathankulam and All: pooled data for the five reservoirs. 
Yield tended to increase linearly with increasing fishing effort. Figure 2 suggests that the selected reservoirs are subjected to sub-optimal fishing pressure and perhaps represent the ascending limb of a possible Schaefar-type curve. However, this does not mean that the fishing effort can be increased indefinitely but indicates that the relationship is valid for ranges in the yield and effort indicated.

This study revealed that the catch per unit effort (CPUE) for a day increased with the increase in number of fishermen per unit area in Vavunikulam, Muthayankattu, Muhathankulam reservoir and decreased with the increase in number of fishermen per unit effort in Puthumurippu and Kalmadu reservoir (Figure 3). However, when the CPUE per day and unit fishing effort of the five reservoirs were considered as a whole, CPUE decreased linearly, though $M$. rosenbergii catch increased linearly. This indicates that even though in all the reservoirs fishermen had targeted more on $M$. rosenbergii, it is still under exploited except for Vavunikulam and Muhathankulam reservoirs.
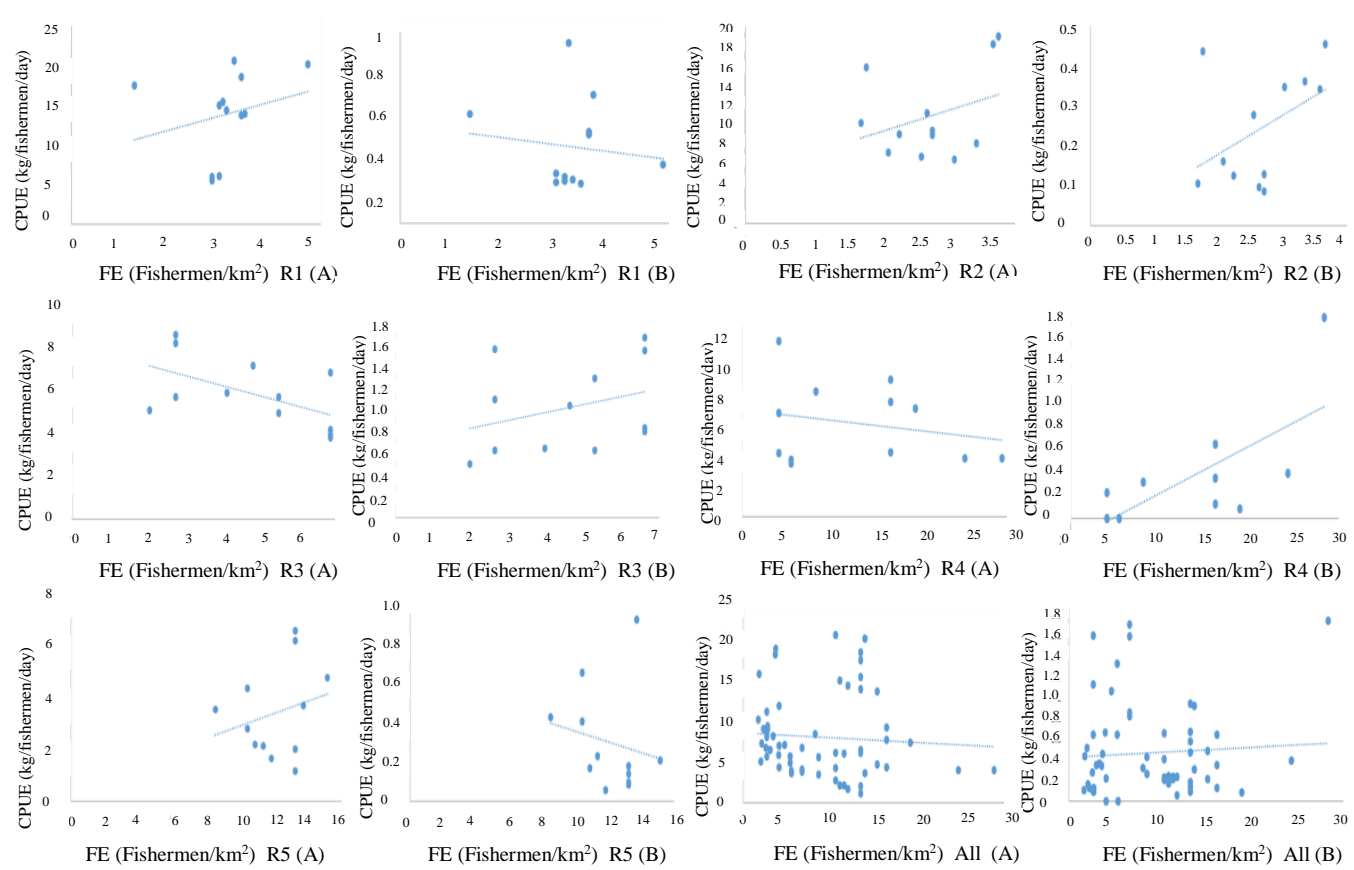

Figure 3. Variation of CPUE with the total catch (A) and M. rosenbergii (B) according to the fishing effort. R1-Vavunikulam, R2-Muthayankattu, R3-Puthumurippu, R4-Kalmadu, R5-Muhathankulam and All-pooled data for the five reservoirs

\section{M. rosenbergii production in selected perennial reservoirs}

Table 2 shows the statistics of production of $M$. rosenbergii in the five reservoirs. Unit productions of $M$. rosenbergii in Vavunikulam, Muthayankattu, Puthumurippu, Kalmadu and Muhathankulam were $5.3 \mathrm{~kg} / \mathrm{ha}, 3.2 \mathrm{~kg} / \mathrm{ha}, 13.6 \mathrm{~kg} / \mathrm{ha}, 21.8 \mathrm{~kg} / \mathrm{ha}, 12.9 \mathrm{~kg} / \mathrm{ha}$, respectively, representing farm-gate values of 6.84, 4.39, 2.1, 1.59, and 2.85 million Sri Lankan rupees, respectively. Total weight basis contribution of $M$. rosenbergii in 2017 was highest in Puthumurippu (20\%) and lowest in Vavunikulam (2.8\%) and Muthayankattu (2.3\%) 
reservoirs, whereas Kalmadu and Muhathankulam recorded a contributions of $9.1 \%$ and $8.4 \%$, respectively. The economic contribution of $M$. rosenbergii harvest to the total economic value of fish production in Vavunikulam, Muthayankattu, Puthumurippu, Kalmadu and Muhathankulam reservoirs was $15.1 \%, 13.5 \%, 72.3 \%, 57.2 \%$ and $59.5 \%$, respectively.

Table 2. Summary of $M$. rosenbergii (FWP) production, stocking density (SD), recapture rate, return on investment (ROI) and economic contribution in five reservoirs ${ }^{\dagger}$

\begin{tabular}{llllll}
\hline Parameter & R1 & R2 & R3 & R4 & R5 \\
\hline Male FWP (kg/ha) & 3.28 & 2.5 & 9.99 & 12.28 & 8.94 \\
Female FWP (kg/ha) & 2.04 & 0.7 & 3.65 & 9.56 & 3.99 \\
Total FWP (kg/ha) & 5.32 & 3.20 & 13.64 & 21.84 & 12.93 \\
Range (Min-Max) (g) & $155-$ & $170-$ & $115-$ & $70-560$ & $65-520$ \\
& 680 & 700 & 635 & & \\
Income (million Rs.) & 6.84 & 4.39 & 2.1 & 1.59 & 2.85 \\
SD (PLs/ ha) & 1058.8 & 597.6 & 662.3 & 2702.7 & 3507.1 \\
Cost (million Rs.) & 2.7 & 1.5 & 0.2 & 0.4 & 1.48 \\
ROI (\%) & 253.3 & 292.7 & 1050 & 397.5 & 192.6 \\
Recapture rate & 1.73 & 1.44 & 6.49 & 3.74 & 1.61 \\
Weight \% & 2.77 & 2.3 & 20 & 9.12 & 8.43 \\
Economic value \% & 15.06 & 13.47 & 72.28 & 57.22 & 59.52 \\
\hline
\end{tabular}

${ }^{\prime}$ R1-Vavunikulam, R2-Muthayankattu, R3-Puthumurippu, R4-Kalmadu, R5-Muhathankulam

Market price of a $M$. rosenbergii PL was Rs. 2 including the transportation cost. The highest return on investment (ROI) of $1050 \%$ was recorded in Puthumurippu with a $6.49 \%$ recapture rate per year. ROI of Kalmadu was $397.5 \%$ with a $3.74 \%$ recapture rate and the Vavunikulam and Muthayankattu major reservoirs had almost similar ROI values of $253.3 \%$ and $292.7 \%$ with recapture rates of $1.73 \%$ and $1.44 \%$, respectively. The lowest ROI of $192.6 \%$ was recorded in Muhathankulam with a recapture rate of $1.61 \%$ probably owing to the characteristic of the catch mostly represent small sized $M$. rosenbergii, which draws relatively lower market price. Despite the recorded low recapture rate, due to the comparatively high market price $M$. rosenbergii production was beneficial for both the investors and the fishers. As a result, fishers had become more interested in fisheries without moving away from fisheries activities to find secondary livelihoods, which was the case before the introduction of $M$. rosenbergii to those reservoirs. After the introduction of $M$. rosenbergii a steady daily income has been ensured for fishers. The lowest individual weights of $M$. rosenbergii recorded in Kalmadu (70 g) and Muhathankulam (65 g) while the highest weights were recorded in large reservoirs; i.e. Vavunikulam (680 g) and Muthayankattu (700 g).

Pearson correlation coefficient revealed that there was a strong negative $(\mathrm{r}=-0.9)$ correlation between area at full supply level (ha) and yield of freshwater prawn $(\mathrm{kg} / \mathrm{ha} / \mathrm{yr})$. The regression relationship of yield $(\mathrm{kg} / \mathrm{ha} / \mathrm{yr})$ and area at FSL (ha) was Yield $=14.222 \mathrm{e}^{-0.001(\mathrm{FSL})}\left(R^{2}=0.8\right)$. Thus, the unit yield is higher in small reservoirs than large reservoirs. On the other hand, with the exclusion of Puthumurippu reservoir, there was a strong positive $(r=0.969)$ correlation between stocking density (SD: PLs/ha) and yield ( $\mathrm{kg} / \mathrm{ha})$. Considering all five reservoirs together, the relationship of yield $(\mathrm{kg} / \mathrm{ha})$ with stocking density $(\mathrm{PLs} / \mathrm{ha})$ was Yield $=0.1036$ $(\mathrm{SD})^{0.6245}$ with a $\left(R^{2}=0.4\right)$. Gear specifications and fishing intensity, reservoir morphology, catchability and the presence of stumps could be the possible reasons for the low $R^{2}$ value.

Age and experience of the fisher, catch from the previous day, degree of poverty and livelihood diversification were the important socio-economic factors that affected the catch of $M$. 
rosenbergii. As revealed in the present study, M. rosenbergii was mostly targeted by young fishers below 40 years of age. Older fishers considered that catching of $M$. rosenbergii as a new fishery which is risky as they have no experience. In addition, the amount of catch from the previous day was the deciding factor for most of the fishers $(87 \%)$ in choosing the location for fishing on the following day. If they got a large catch on the previous day, some fishers choose the same location for fishing on the next day too. Instead, some others go to little faraway places to catch fish on the next day. Also, the fishers that are poor tend to choose catch tilapia and carps over $M$. rosenbergii because $M$. rosenbergii is required to be caught at the bottom of the reservoir, which has a risk of catching no fish at all. Therefore, to ensure that they get some income for their survival, poor fishers choose to fish for tilapia and carps. Also, fishers who have diversified their livelihoods and mostly who are income secured, choose to take the risk and invest in the catching of $M$. rosenbergii. On contrary, poor fishers in Puthumurippu focused on catching $M$. rosenbergii because culture based fishery was relatively new to Puthumurippu compared to the other reservoirs and hence, fisheries production including Tilapia was comparatively low. Therefore, they focused more on M. rosenbergii due to its high value.

Hydro-climatic factors that contributed fluctuations in fish catches were low rainfall, strong winds and high temperature. As evident from the meteorological data and responses of fishers, rainfall has been significantly low in the reservoir areas in the past five years resulting in low water levels as considerable amount of water is diverted for irrigation purposes. Fishermen get benefitted from low water levels of reservoirs in a short run. However, in the long run low water levels lead to low species diversity in reservoirs due to the combined effects of low water levels, increased temperature and high fishing intensity. Thus, the reasons for the observation of fish deaths observed in 2016 in Muthayankattu, Kalmadu and Muhathankulam reservoirs could be due to the effects of low water level, high temperature, increase in fish biomass and vegetation, low feed availability and oxygen depletion. Strong winds limit the access to all areas of the reservoir for fishing and hence, fishers mostly choose areas that are close to the landing site. Therefore, fishing pressure on those nearby areas was higher than the other areas of the reservoir. Further, fishermen refrain from applying gear close to areas where there are tree trumps and vegetation, which is the potential area for $M$. rosenbergii, in order to avoid damaging the gear. This practice also has resulted in lower fish production in large reservoirs during the months with strong winds. Production in the Puthumurippu reservoir was not significantly affected by strong winds as it was a small reservoir and applying gear was easy.

Gilling, wedging, snagging and entangling are the four methods used for catching fish using a gillnet (Fonseca et al., 2005). M. rosenbergii is mostly caught in gillnet by entangling mostly by their claw, rostrum spines and all parts of the body resulted by struggling to escape. Further, presence of body projections such as, teeth or spines, facilitate significant proportion of prawns being entangled in gillnets (Sparre and Venema, 1998). Mesh size, hanging ratio, twine thickness and the colour of twine are the characteristics of gillnets that affect the selectivity and catch size (Fonseca et al., 2005; Holst et al., 2002; Tweddle and Bodington, 1988). The significant contribution of $M$. rosenbergii to the harvest in the selected reservoirs is also partly due to the change in fishing gear technique. In those reservoirs, gillnets are generally set in the evening and taken out on the next day morning. Therefore, during the night time deep and turbid water contribute to low visibility of the net. Red, green or blue colour dyes are applied in gillnets depending on the reservoirs. Different hanging ratios change the shape of the mesh and slackness of the net. Since $M$. rosenbergii has a higher market value than other fish species, fishers have strategically modified their gear by adding more sinkers with a few floats to reach the bottom and to reduce stretch due to speedy backward movement of $M$. rosenbergii when they touch or sense of strange objects. Usage of modified gillnets in small reservoirs is higher 
than large reservoirs. Since Catla, Rohu and tilapia inhabit the surface and column of the reservoir (Edirisinghe, 2007), the likelihood of catching them is low after the introduction of $M$. rosenbergii. Thus, fin-fish had become a bi-catch particularly in the small reservoirs.

The observation of Puthumurippu perennial reservoir was comparable to the observation of a study conducted in Pak Mun Dam, which is a major reservoir of 4909 ha in Thailand (Sripatrprasite and Lin, 2003). The average weight of the male M. rosenbergii in Puthumurippu was $389.0 \pm 5.9 \mathrm{~g}$ while in the Pak Mun Dam reservoir average weight of the M. rosenbergii harvested during the one-year study period was $236.5 \pm 102.1 \mathrm{~g}$. In terms of $M$. rosenbergii production, stocking of 2 million $M$. rosenbergii PL resulted in a production of $3 \mathrm{~kg} / \mathrm{ha} / \mathrm{yr}$ in the Pak Mun Dam reservoir (Sripatrprasite and Lin, 2003). When the stocking was increased to 40 million PLs, the production reached up to $11.5 \mathrm{~kg} / \mathrm{ha} / \mathrm{yr}$ (Jutagate and Kwangkhang, 2015). In the present study, Vavunikulam and Muthayankattu reservoirs had a yield of 2.66 $\mathrm{kg} / \mathrm{ha} / \mathrm{yr}$ and $1.6 \mathrm{~kg} / \mathrm{ha} / \mathrm{yr}$ respectively, while Puthumurippu and Kalmadu reservoirs had higher yields of $13.64 \mathrm{~kg} / \mathrm{ha} / \mathrm{yr}$ and $14.56 \mathrm{~kg} / \mathrm{ha} / \mathrm{yr}$ followed by Muhathankulam with a yield of $7.76 \mathrm{~kg} / \mathrm{ha} / \mathrm{yr}$.

Asoka et al. (2015) reported that in Sri Lankan reservoirs, the highest and the lowest mean annual yield of freshwater prawn were from minor perennial and major perennial reservoirs, with a yields of $41.3 \mathrm{~kg} / \mathrm{ha}$ and $3.4 \mathrm{~kg} / \mathrm{ha}$ stocking densities of $2062 \mathrm{PL} / \mathrm{ha}$ and $222 \mathrm{PL} / \mathrm{ha}$ representing yield contributions of $3 \%$ and $1.6 \%$, respectively. Despite the difference in yield both major and minor perennial reservoirs contributed significantly to the income of the fishers. The recapture rate of stocked fish is generally high with an average of over $10 \%$, and could be as high as $50 \%$ in communal ponds and swamps, whereas the recapture rate of the $M$. rosenbergii is generally poor and less than $5 \%$ (Jutagate and Rattanachai, 2010). The highest recapture rate of about $10 \%$ for $M$. rosenbergii was recorded in a natural lake, Beung Borapet in Thailand, which had been stocked in 1995 with 3 million PLs (Jutagate and Kwangkhang, 2015). Similarly, in the present study Puthumurippu recorded a recapture rate of $6.49 \%$. The recapture rate in large reservoirs is comparatively lower than small reservoirs. Pak Mun Dam major reservoir showed a lower recapture of $1 \%$ (Sripatrprasite and Lin, 2003). Similarly, in the present study large reservoirs of Vavunikulam (1.73\%) and Muthayankattu (1.44\%) showed a slightly higher recapture rate.

The economic benefit from $M$. rosenbergii was higher than any other stocked fish species in the reservoirs. Sripatrprasite and Lin (2003) reported that catches of prawn contributed $53.8 \%$ to the total fish catch by weight and $97 \%$ to the economic value of the landings in the Pak Mun Dam Reservoir. A five-year monitoring program undertaken by Chumnongsittsthum (1987) revealed that the profit of stocked $M$. rosenbergii in Ubolratana reservoir was $382 \%$. Jutagate and Kwangkhang (2015) reported a $722 \%$ profit only with a recapture rate of $1.8 \%$ of $M$. rosenbergii in Bangphra reservoir. The high economic return reflects the high market demand of $M$. rosenbergii and there is a large difference between the cost of production of seed and market price of the adult freshwater prawns. In the present study, the cost of a $M$. rosenbergii PL was Rs. 2.00, which was equivalent to the price of a fingerling of major carps or GIFT tilapia. The farm-gate prices of the stocked carps and tilapia ranged between Rs. 120-200 / kg, whereas the market price of $M$. rosenbergii ranged from Rs. $700-1200 / \mathrm{kg}$. Stocked $M$. rosenbergii, therefore, benefits traders at various levels in the market chain and provides employment opportunities and income for all related sectors (Jutagate and Kwangkhang, 2015). Similar experiences of introducing $M$. rosenbergii has also been recorded in Kerala, India where it contributed to development of fisheries in reservoirs (Laxmappa and Krishna, 2015). Thus, stocking programs of $M$. rosenbergii could successfully contribute to the improvement of fisheries in the five selected reservoirs. 


\section{CONCLUSIONS}

The introduction of $M$. rosenbergii as culture-based fisheries in the selected five reservoirs has achieved considerable success, especially in terms of economic benefits. Even though the recapture rate was low, catching of $M$. rosenbergii improved the livelihood of fishers while increasing their interest in fisheries. Size of the reservoir, stocking density, fishing intensity and gear specification, rainfall, wind and socio-economic factors significantly influenced the catch of M. rosenbergii in the selected reservoirs. Further investigations on yield, growth rate, and factors affecting the growth of $M$. rosenbergii in reservoirs in Northern Province over time need to be carried out to improve culture based fisheries to utilize the reservoirs in a sustainable manner and to improve livelihoods of fisher families. Findings of the present study would be useful to aqua-culturists and fisheries managers for the establishment of culture-based fisheries in reservoirs using $M$. rosenbergii under extensive culture.

\section{ACKNOLEDGEMENT}

The authors would like to thank the fishermen who cooperated in conducting this study, the staffs of NAQDA Regional Office, Northern Province and Divron Bioventures (Pvt.) Ltd., who shared data and lent logistic support.

\section{REFERENCES}

Amarasinghe, U., Duncan, A., Moreau, J., Schiemer, F., Simon, D. and Vijverberg, J. (2001). Promotion of sustainable capture fisheries and aquaculture in Asian reservoirs and lakes. Hydrobiologia. 458, 181-190.

Amarasinghe, U. (2014). Fisheries resources in alleviation of hunger and malnutrition in Sri Lanka - accomplishment and challenges. Sri Lanka Journal of Aquatic Science. 18,1-15.

Asoka, J.M., Chandraratne, P.N. and Amarasinghe, U.S. (2015). Production performance of Macrobrachium rosenbergii in culture based fisheries in perennial reservoirs. Proceedings of the Twenty-first Scientific Sessions of the Sri Lanka Association for Fisheries and Aquatic Resources. Auditorium of National Aquatic Resources Research and Development Agency, Colombo 15, Sri Lanka.

Brown, C. and Day, R.L. (2002). The future of stock enhancements: lessons for hatchery practice from conservation biology. Fish and Fisheries, 3(2),79-94.

Chumnongsittsthum, B., (1987). Stocking of giant freshwater prawn, Macrobrachium rosenbergii in Ubolratana Reservoir during 1981-1986. Proceedings of the seminar on fisheries 1987 of the Department of Fisheries, Department of Fisheries, Bangkok, pp. 279 285.

Cowx, I.G. (1999). An appraisal of stocking strategies in the light of developing country constraints. Fisheries Management and Ecology, 6,21-34.

Craig, J.F., Sharma, A. and Smiley, K. (1985). The variability in catches from multi-mesh gillnets fished in three Canadian lakes. Journal of Fish Biology 28,671-688. 
De Silva, S.S. (1988). Reservoirs of Sri Lanka and their fisheries. FAO Fisheries Technical Paper 298, 128.

De Silva, S.S. (1996). The Asian inland fishery with special reference to reservoir fisheries: A reappraisal. Pp. 321- 332. In: Schiemer F., Boland K.T. (eds.) Perspectives in tropical limnology. SPB Academic Publishing, Amsterdam, the Netherlands.

Edirisinghe, U. (2007). Freshwater Capture Fisheries and Aquaculture of Sri Lanka. Anura Press, Kurunegala, Sri Lanka.

FAO. (1999). Review of the state of world fishery resources: Inland fisheries. FAO Fish. Circ. No. 942. Rome, FAO. 54 pp.

FAO. (2017). FAO Aquaculture Newsletter. No. 56 (April). Rome.

Fonseca, P., Martins, R., Campos, A. and Sobral, P. (2005). Gill-net selectivity off the Portuguese western coast. Fisheries Research 73 (3),323-339.

Gray, C.A., Broadhurst, M.K. Johnson, D.D. and Young, D.J. (2005). Influences of hanging ratio, fishing height, twine diameter and material of bottom-set gillnets on catches of dusky flathead Platycephalus fuscus and non-target species in New South Wales, Australia. Fisheries Science 71,1217-1228.

Jutagate, T. and Kwangkhang, W. (2015). Culture-based fishery of giant freshwater prawn: Experiences from Thailand. In: Sena S. De Silva, B.A. Ingram and S. Wilkinson (eds.), Perspectives on culture-based fisheries developments in Asia, pp. 91-97. Network of Aquaculture Centers in Asia-Pacific, Bangkok, Thailand.

Jutagate, T., and Rattanachai, A. (2010). Inland fisheries resource enhancement and conservation in Thailand. RAP Publication 2010/22, pp. 133-150. Regional Office for Asia and the Pacific, FAO, Bangkok.

Holst, R., Wileman, D., and Madsen, N. (2002). The effects of twine thickness on the size selectivity and fishing power of Baltic cod gill nets. Fisheries Research 56 (3), 303-312.

Laxmappa, B. and Krishna, S.M. (2015). Polyculture of the freshwater prawn Macrobrachium malcolmsonii (H.M. Edwards) in Koilsagar reservoir of Mahabubnagar district (TS), India. International J. Fish. \& Aqua. Stud. 2(4), 147-152.

Li, J. (1999). An appraisal of factors constraining the success of fish stock enhancement programmes. Fisheries Management \& Ecology, 6(2), 161-169.

NAQDA, (2018). NAQDA website, Retrieved 14th of April 2018. (http://www.naqda.gov.lk/statistics)

New, M.B. (2017). Update on global farmed freshwater prawn production statistics. In: Giant prawn conference 2017; Thailand. (March), 1-12.

Pet, J.S., van Densen, W.L.T., and Vijverberg, J. (1999). Management options for the exploitation of introduced tilapia and small indigenous cyprinids in Sri Lankan reservoirs. In: Fish and fisheries of lakes and reservoirs in Southeast Asia and Africa (ed. W.L.T. van Densen and M.J. Morris), pp. 159-185. Westbury Publishing, Otley. 
Quirós, R. and Boveri, M.B. (1999). Fish effects on reservoir tropical relationships. Pp. 529 546. In: Tundisi, J. G. and M. Straškraba. (Eds.). Theoretical reservoir ecology and its applications. São Carlos, International Institute of Ecology.

Sparre, P., and Venema, S.C. (1998). Introduction to tropical fish stock assessment. Part 1. Manual. FAO Fisheries Technical Paper No. 306.1: Rev. 2. FAO, Rome.

Sripatrprasite, P. and Lin, C. (2003). Stocking and recapture of freshwater prawn (Macrobrachium rosenbergii De Man) in a run-of-river type dam (Pak Mun Dam) in Thailand. Asian Fish. Sci. 16, 167-174

Tweddle, D., and Bodington, P. (1988). A comparison of the effectiveness of black and white gillnets in Lake Malawi, Africa. Fisheries Research 6 (3), 257-269.

Welcomme, R.L. (2001). Inland fisheries: Ecology and management. FAO Rome and Fishing News Books, Blackwell Science, Oxford, UK. 